\title{
IMPLEMENTASI WIRELESS SENSOR NETWORK PROTOTYPE SEBAGAI FIRE DETECTOR MENGGUNAKAN ARDUINO UNO
}

\section{PROTOTYPE IMPLEMENTATION OF WIRELESS SENSOR NETWORK AS FIRE DETECTOR USING ARDUINO UNO}

\author{
Ratna Susana, S.T. ,M.T. ${ }^{1}$, Arsyad Ramadhan D., S.T., M.T. ${ }^{2}$, Sayidino Aqli ${ }^{3}$ \\ ${ }^{1,2,3}$ Teknik Elektro Peminatan Teknik Telekomunikasi, Fakultas Teknologi Industri, \\ Institut Teknologi Nasional \\ 1'ratnassn@yahoo.com, ${ }^{2}$ arsyaddarlis@gmail.com, ${ }^{3}$ sayidino.aqli@gmail.com
}

\begin{abstract}
Abstrak
Sistem wireless sensor network ini dibangun untuk mendeteksi kebakaran berupa api dan asap. Sistem mendeteksi api dan asap menggunakan sensor api dan asap yang dihubungkan ke mikrokontroler Arduino UNO. Hasil pendeteksian kemudian dikirimkan melalui SMS (Short Message Service) sebagai notifikasi ke dua user yaitu user 1 (pemadam kebakaran) dan user 2 (tim investigasi kebakaran). User 1 (pemadam kebakaran) menerima notifikasi berupa alarm kebakaran. User 2 (tim investigasi kebakaran) menerima notifikasi berupa posisi awal terjadinya kebakaran. Dari hasil penelitian didapat keberhasilan penerimaan notifikasi diatas 80 persen dengan waktu kurang dari 10 detik, sehingga dapat mempercepat respon tanggap dari dua user tersebut (pemadam kebakaran dan tim investigasi kebakaran) dibandingkan menunggu seseorang menyaksikan kebakaran dan melakukan panggilan telepon.
\end{abstract}

Kata Kunci : arduino, kebakaran, sensor, SMS, wireless sensor network.

\begin{abstract}
This wireless sensor network system constructed to detect fires in the form of fire and smoke. This system detect fire and smoke using a fire and smoke sensor which is connected to microcontroller Arduino UNO. The results of detection then transmitted via SMS (Short Message Service) as a notification to two users which is user 1 (firefighters) and user 2 (fire investigation team). User 1 (firefighters) received a fire alarm notification. User 2 (fire investigation team) received an initial position of fire notification. The result of this research is 80 percent notification succed to received within less than 10 seconds, so it can expedite the two users response (firefighters and fire investigation team) than to wait for someone to watch the fire and make phone calls.
\end{abstract}

Keywords : arduino, fire, sensor, SMS, wireless sensor network.

\section{PENDAHULUAN}

Kebakaran merupakan salah satu bencana yang sering terjadi didaerah pemukiman penduduk yang menyebabkan terjadinya korban jiwa dan kerugian material. Hal ini dikarenakan kurangnya proteksi aktif dan pasif terhadap gejala dini kebakaran (api dan asap). Salah satu sistem proteksi pasif adalah pendeteksian gejala dini kebakaran (api dan asap) menggunakan wireless sensor network. Wireless sensor network merupakan bagian utama dalam mengumpulkan informasi yang diperlukan oleh jaringan yang terdedikasi baik itu di dalam bangunan industri maupun sistem otomasi transportasi.[6] 
Jusak dan Fardhan Arkan melakukan penelitian Wireless Sensor Network (WSN) menggunakan Zigbee 802.15.4 sedangkan M. Yanuar Hariyawan menggunakan Paralax 433MHz. Zigbee menggunakan jaringan WiFi (Wireless Fidelity) sebagai media komunikasi dengan frekuensi 2,4 GHz[2]. Sedangkan Paralax 433MHz menggunakan Radio Frekuensi dengan jangkauan 250 meter (NLOS / No Line Of Sight) dan 350 meter (LOS / Line Of Sight).[4][2]

Pada penelitian ini mencoba membuat implementasi wireless sensor network prototype sebagai fire detector menggunakan Arduino UNO. Pendeteksian terhadap kebakaran menggunakan sensor api dan sensor asap. Sedangkan media komunikasi WSN yang digunakan adalah jaringan komunikasi seluler GSM (Global System for Mobile Communication). Penerima notifikasi (user) adalah pemadam kebakaran dan tim investigasi kebakaran. Notifikasi yang dikirimkan ke pemadam kebakaran berupa alarm kebakaran dan diharapkan mempercepat respon tanggap dari mereka. Sedangkan pemberian notifikasi ke tim investigasi kebakaran berupa pemberitahuan dan posisi atau titik awal mula terjadinya kebakaran agar mempermudah pekerjaan mereka dalam menentukan titik mula terjadinya kebakaran.. Dengan batasan ruangan pendeteksian sebanyak 3 ruangan dengan ukuran sebesar $15 \mathrm{~cm} \times 15 \mathrm{~cm} \times 15 \mathrm{~cm}$, penempatan sensor tidak diperhitungkan, dan sensor yang digunakan sebagai pendeteksian yaitu sensor api dan sensor asap.

\section{DASAR TEORI}

Wireless sensor network terdiri dari 3 komponen utama yaitu node, gateway, dan software. Node didistribusikan melalui antarmuka seperti sensor untuk memantau aset maupun lingkungan sekitar. Data yang diperoleh kemudian dikirimkan secara nirkabel melalui gateway, dimana bisa dioperasikan secara bebas atau dihubungkan ke sebuah host system dimana data bisa dikumpulkan, diproses, dan ditampilkan dengan menggunakan software.[12]

Arduino adalah sebuah platform elektronika terbuka untuk umum berdasarkan perangkat keras dan perangkat lunak yang mudah digunakan. Perangkat ini bertujuan agar semua orang bisa membuat sebuah proyek yang interaktif untuk digunakan. Arduino mampu mendeteksi lingkungan sekitarnya dengan cara menerima input dari sensor dan mempengaruhi lingkungan sekitarnya dengan mengontrol lampu, motor dan aktuator. Arduino dapat diprogram dengan menggunakan arduino development environment.[11]

GSM (Global System for Mobile Communication) adalah sebuah teknologi komunikasi selular yang bersifat digital. Teknologi GSM banyak diterapkan pada komunikasi bergerak, khususnya mobile station. Pada mobile station terdapat fitur yang bisa digunakan pada sistem komunikasi seluler GSM yaitu SMS (Short Message Service). SMS merupakan sebuah pesan singkat yang berisikan maksimum 160 karakter. Alur pengiriman SMS pada standar teknologi GSM adalah sebagai berikut :

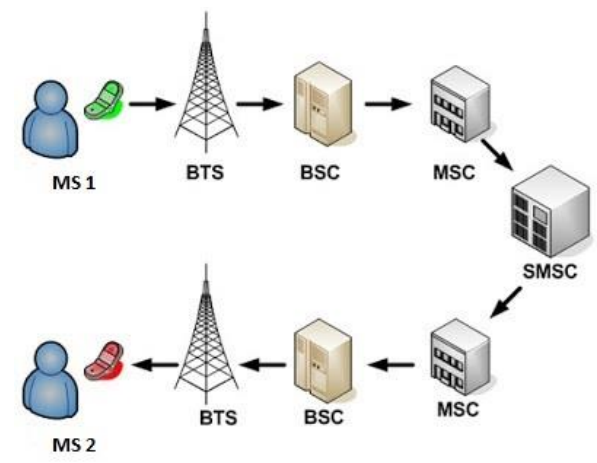

Gambar 1. Alur Pengiriman SMS

Keterangan Gambar 1 :

a. $\quad$ MS (Mobile Station). 
b. BTS (Base Transceiver Station).

c. BSC (Base Station Controller).

d. $\quad$ MSC (Mobile Switching Center).

e. SMSC (Short Message Service Center).

Gambar 1 menunjukkan bagaimana alur pengiriman SMS dari MS 1 ke MS 2. Ketika pengguna mengirim SMS, maka pesan dikirim ke MSC melalui jaringan seluler yang tersedia yang meliputi tower BTS yang sedang meng-handle komunikasi MS 1, lalu ke BSC, kemudian sampai ke MSC. MSC kemudian mem-forward lagi SMS ke SMSC untuk disimpan. SMSC kemudian mengecek (pada HLR - Home Location Register) untuk mengetahui apakah mobile station tujuan sedang aktif dan dimanakah mobile station tujuan tersebut. Jika mobile station sedang tidak aktif maka pesan tetap disimpan di SMSC itu sendiri, menunggu MSC memberitahukan bahwa mobile station sudah aktif kembali untuk kemudian SMS dikirim dengan batas maksimum waktu tunggu yaitu validity period dari pesan SMS itu sendiri. Jika mobile station tujuan aktif maka pesan disampaikan MSC lewat jaringan yang sedang meng-handle penerima (BSC dan BTS). Pada dasarnya mobile station dan GSM/CDMA modem (modulator demodulator) terdapat suatu komponen wireless modem/engine yang dapat diperintah antara lain untuk mengirim suatu pesan SMS dengan protokol tertentu. Standar perintah tersebut dikenal sebagai AT command, sedangkan protokolnya disebut sebagai PDU (Protokol Data Unit). Melalui AT command dan PDU inilah komputer/mikrokontroler mengirim/menerima SMS secara otomatis.

AT Command atau juga bisa disebut perintah AT (attention) yang dikirimkan ke alat yang terhubung pada serial port. AT Command merupakan bagian dari Hayes command. Pada AT command terdapat macam-macam perintah yang bisa kita kirimkan ke alat yang terhubung dengan serial port. Contoh perintah tersebut bisa dilihat pada Tabel 1.

Tabel 1. Contoh Perintah AT Command

\begin{tabular}{|c|c|}
\hline Perintah & Penjelasan \\
\hline AT+CMGD & Menghapus pesan teks / SMS \\
\hline AT+CMGF & Memilih format pesan teks / SMS \\
\hline AT+CMGR & Membaca pesan teks / SMS \\
\hline AT+CMGW & Mengirim pesan teks / SMS \\
\hline AT+CMSS & Mengirim pesan teks dari penyimpanan \\
\hline
\end{tabular}

\section{PERANCANGAN dan PENGUJIAN}

\subsection{Perancangan Sistem}

Perangkat keras yang akan digunakan untuk membuat prototype sistem wireless sensor network sebagai fire detector yaitu sensor api, sensor asap, Arduino UNO, GSM shield, telepon seluler dan catu daya. Pada saat sensor mendeteksi kedua kondisi awal secara bersamaan, mikrokontroler Arduino UNO akan memproses dan mengolah data tersebut. Kemudian mikrokontroler Arduino UNO mengirim data tersebut ke GSM Shield untuk dikirimkan ke user berupa notifikasi dengan format text message atau SMS (Short Message Service). Terdapat dua user yang menerima notifikasi yaitu user 1 (pemadam kebakaran) dan user 2 (tim investigasi kebakaran). User 1 (pemadam kebakaran) menerima notifikasi alarm kebakaran. Sedangkan user 2 (tim investigasi kebakaran) menerima notifikasi posisi awal kebakaran. Adapun sistem ini menggunakan prototype ruangan dengan ukuran tiap ruangannya $15 \mathrm{~cm} \times 15 \mathrm{~cm} \times 15 \mathrm{~cm}$. 


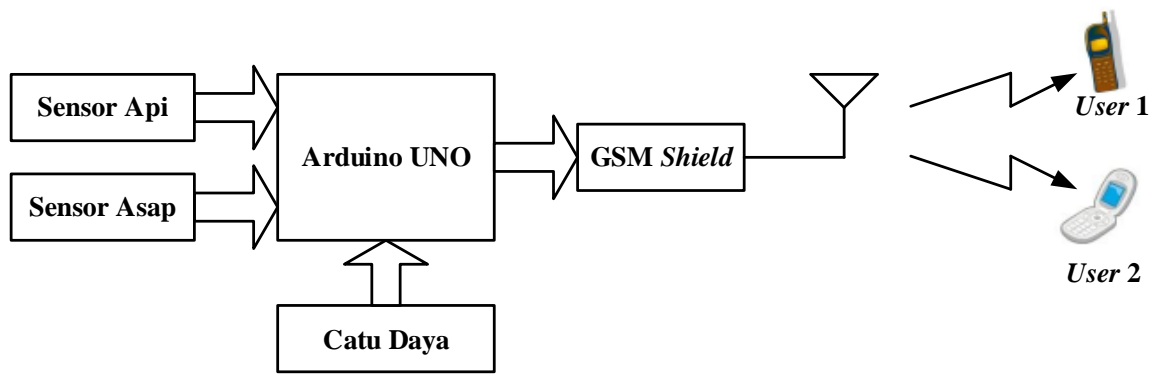

Gambar 2. Blok Diagram Sistem

\subsection{Cara Kerja Sistem}

Sistem ini bekerja dengan cara seperti yang ditunjukkan pada Gambar 3.

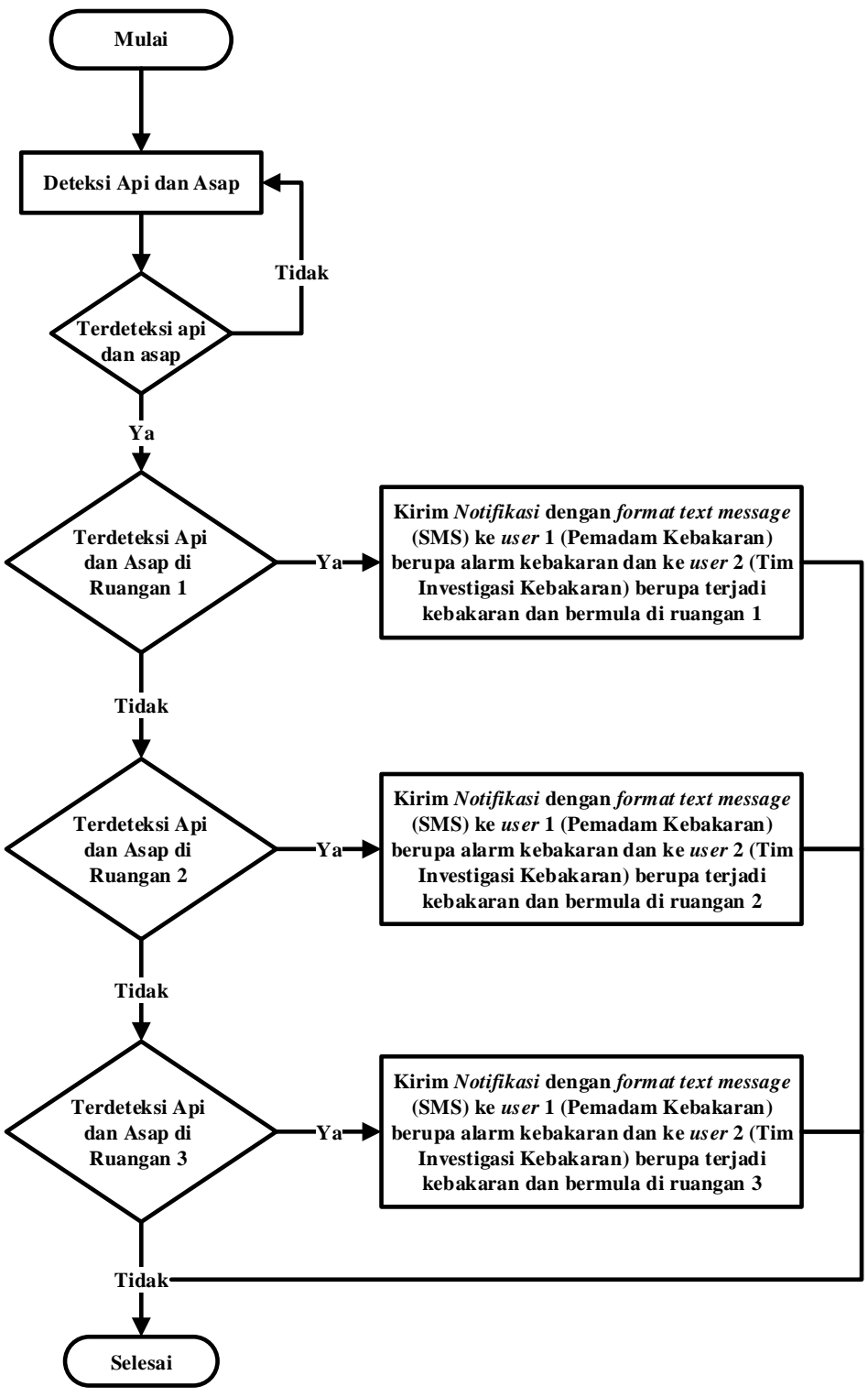

Gambar 3. Flowchart Sistem

Sensor mendeteksi api dan asap secara terus-menerus di ketiga ruangan prototype. Pada saat sensor api dan asap di ruangan 1 mendeteksi api dan asap secara bersamaan maka akan 
mengirimkan notifikasi alarm ke user 1 dan posisi awal terjadinya kebakaran dari ruangan 1 ke user 2. Apabila sensor api dan asap mendeteksi api dan asap secara bersamaan di ruangan 2 maka akan mengirimkan notifikasi alarm kebakaran ke user 1 dan posisi awal terjadinya kebakaran dari ruangan 2 ke user 2. Sedangkan saat sensor api dan asap mendeteksi api dan asap secara bersamaan di ruangan 3 maka akan mengirimkan notifikasi alarm kebakaran ke user 1 dan posisi awal terjadinya kebakaran dari ruangan 3 ke user 2 .

\subsection{Realisasi Perancangan Sistem}

Dari perancangan sistem dapat direalisasikan sistem seperti yang ditunjukkan pada Gambar 4.

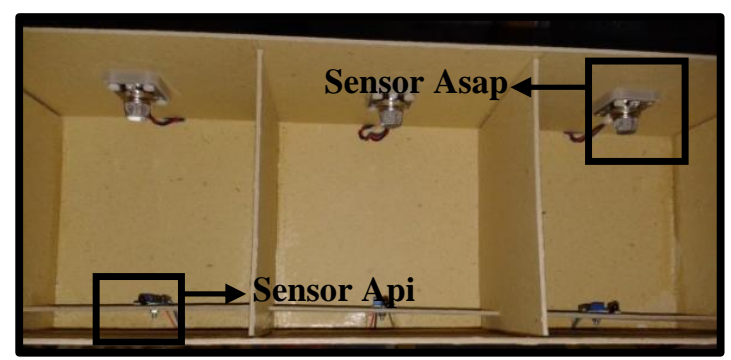

(a)

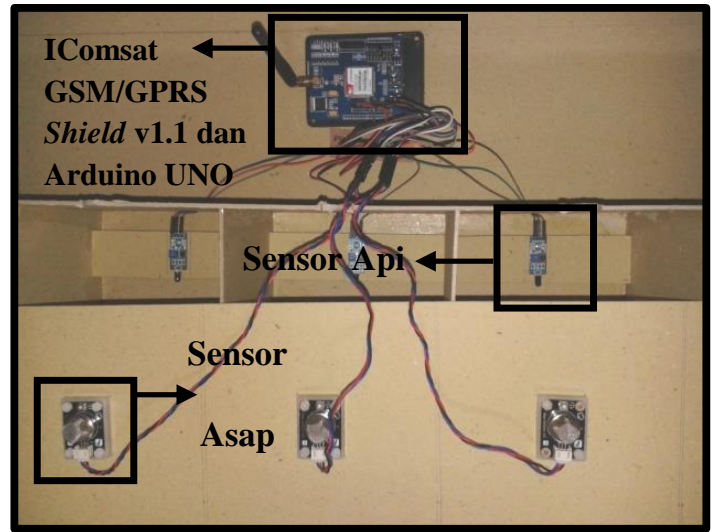

(b)

Gambar 4. Realisasi sistem (a) Tampak Depan dan (b) Tampak Atas

\subsection{Pengujian Keluaran Sistem}

\subsubsection{Sensor Api}

Pengujian dilakukan dengan memberikan sumber (cahaya matahari, lampu, dan api) tepat didepan receiver sensor setelah sensor api dihubungkan ke Arduino UNO. Sumber api diukur untuk jarak $8 \mathrm{~cm}$ (didalam ruangan prototype) dan $30 \mathrm{~cm}$ (diluar ruangan prototype). Adapun pengukuran juga dilakukan dengan menggunakan sudut 15 derajat dan 30 derajat. Hasil pengukuran pada Tabel 2 menunjukkan bahwa intensitas cahaya menurun terhadap jarak yang semakin jauh. Intensitas cahaya ini mempengaruhi besarnya tegangan yang terukur pada sensor api seperti yang ditunjukkan pada Tabel 3. Tegangan yang terukur pada sensor api menurun pada jarak yang semakin dekat saat diberikan sumber api dibandingkan terhadap sumber lampu. Namun tegangan yang terukur dengan sumber api dan tegangan yang terukur dengan sumber cahaya matahari saling mendekati yaitu sebesar kurang dari 0,15 volt. Oleh karena itu cahaya matahari merupakan noise terbesar dalam pendeteksian untuk sensor api. Tegangan yang terukur pada sensor api berupa tegangan DC seperti yang ditunjukkan Gambar 5.

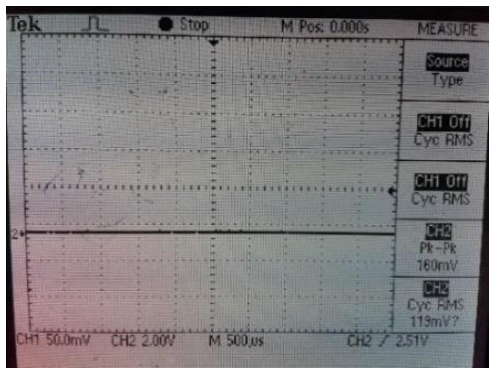

Gambar 5. Keluaran Sensor Api pada Osiloskop 
Tabel 2. Intensitas Cahaya Api Terhadap Jarak

\begin{tabular}{|c|c|c|c|c|c|}
\hline \multirow{2}{*}{ Sumber } & Cahaya & \multicolumn{5}{|c|}{ Api } \\
\cline { 3 - 6 } & Matahari & $\mathbf{8 ~ c m}$ & $\mathbf{1 0} \mathbf{~ c m}$ & $\mathbf{2 0} \mathbf{~ c m}$ & $\mathbf{3 0} \mathbf{~ c m}$ \\
\hline $\begin{array}{c}\text { Intensitas } \\
\text { Cahaya (Lux) }\end{array}$ & 1000 & 475 & 450 & 400 & 380 \\
\hline
\end{tabular}

Tabel 3. Output Sensor Api Dengan Berbagai Sumber

\begin{tabular}{|c|c|c|c|c|c|c|}
\hline \multirow{2}{*}{ Sumber } & \multirow{2}{*}{$\begin{array}{c}\text { Tanpa } \\
\text { Sumber }\end{array}$} & \multirow{2}{*}{$\begin{array}{c}\text { Cahaya } \\
\text { Matahari }\end{array}$} & $\begin{array}{c}\text { Jarak 90 } \\
\text { cm }\end{array}$ & $\begin{array}{c}\text { Jarak } \\
\mathbf{2 5 0} \mathbf{~ c m}\end{array}$ & $\begin{array}{c}\text { Jarak 8 } \\
\text { cm }\end{array}$ & $\begin{array}{c}\text { Jarak 30 } \\
\text { cm }\end{array}$ \\
\hline $\begin{array}{c}\text { Rata-Rata } \\
\text { Tegangan } \\
\text { (volt) }\end{array}$ & 4,63 & 0,15 & 1,82 & 4,07 & 0,13 & 3,22 \\
\hline
\end{tabular}

Tabel 4. Output Sensor Api dengan Sudut

\begin{tabular}{|c|c|c|c|c|}
\hline Jarak & \multicolumn{2}{|c|}{$\mathbf{8 ~ c m}$} & \multicolumn{2}{c|}{ Jarak 30 cm } \\
\hline Sudut & $\mathbf{1 5}$ derajat & $\mathbf{3 0}$ derajat & $\mathbf{1 5}$ derajat & $\mathbf{3 0}$ derajat \\
\hline Rata-Rata Tegangan (volt) & 0,17 & 0,19 & 3,18 & 3,40 \\
\hline
\end{tabular}

\subsubsection{Sensor Asap}

Pengujian dilakukan dengan cara memberikan asap ke sensor asap setelah dihubungkan ke mikrokontroler Arduino UNO. Dari pengukuran yang ditunjukkan pada Tabel 4 bahwa tegangan yang terukur pada sensor asap meningkat pada saat diberikan asap. Asap yang digunakan adalah asap rokok.

Tabel 5. Output Sensor Asap

\begin{tabular}{|c|c|c|}
\hline Sumber & Tanpa Asap & Asap \\
\hline Rata-Rata Tegangan (volt) & 0,72 & 4,48 \\
\hline
\end{tabular}

\subsubsection{GSM Shield}

Pengujian dilakukan setelah menghubungkan GSM Shield ke mikrokontroler Arduino UNO. Dari pengukuran pada Tabel 5 menunjukkan bahwa SMS berhasil dikirim menggunakan GSM Shield.

Tabel 6. Output GSM Shield

\begin{tabular}{|c|c|}
\hline Persentase Keberhasilan Diterima & 100 \\
\hline Waktu Rata-Rata (detik) & 6,3 \\
\hline
\end{tabular}

\subsubsection{Sistem Secara Keseluruhan}

Pengujian sistem dilakukan dengan cara memberikan sumber berupa api dan asap pada ketiga ruangan dengan ukuran $15 \mathrm{~cm}$ x $15 \mathrm{~cm}$ x $15 \mathrm{~cm}$. Pengukuran juga dilakukan dengan dua cara yaitu tanpa sudut dan dengan sudut. Pengukuran tanpa sudut dengan cara memberikan sumber api tepat didepan receiver sensor. Sedangkan pengukuran dengan sudut dilakukan dengan cara memberikan sumber api dengan sudut sebesar 15 derajat. Selain itu pengukuran juga dilakukan dengan memberikan sumber api dengan jarak sejauh $8 \mathrm{~cm}$ (didalam ruangan) dan $30 \mathrm{~cm}$ (diluar ruangan). Pemberian sumber asap setelah memberikan sumber api sesuai dengan jarak pengukuran. Sumber api menggunakan lilin. 


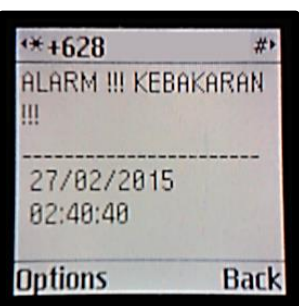

(a)

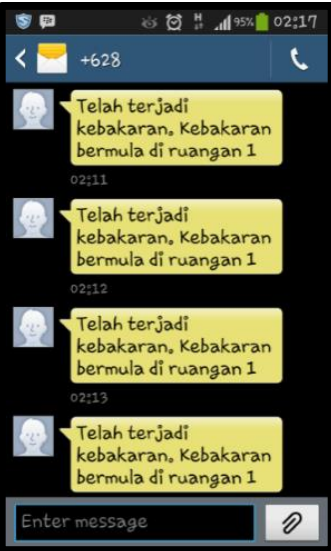

(b)

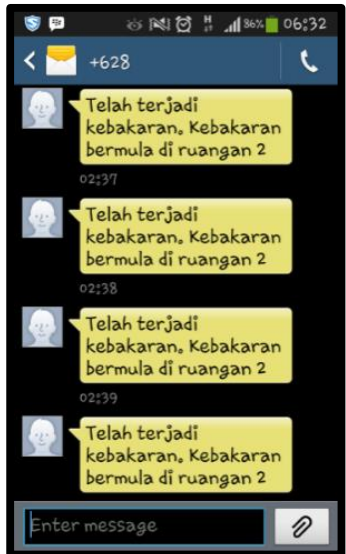

(c)

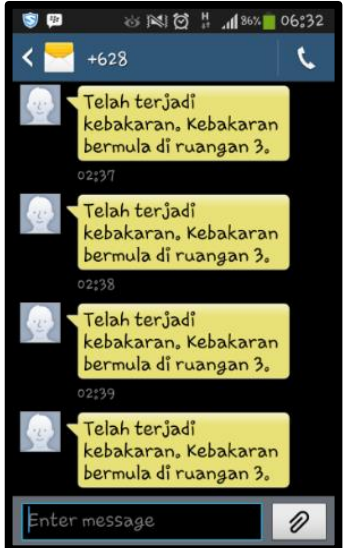

(d)

Gambar 6. Tampilan notifikasi (a) User 1 Di Semua Ruangan, (b) User 2 Di Ruangan 1, (c) User 2 Di Ruangan 2, dan (d) User 2 Di Ruangan 3

Tabel 7. Output Sistem Dengan Sumber Api Sejauh $8 \mathrm{~cm}$ dari Receiver Sensor

\begin{tabular}{|c|c|c|c|c|c|}
\hline \multirow{2}{*}{ Jarak 8 cm } & \multicolumn{2}{c|}{ Waktu Rata-Rata } & \multicolumn{2}{c|}{ Keberhasilan Diterima } \\
\cline { 3 - 6 } \multicolumn{2}{|c|}{} & $\begin{array}{c}\text { Tanpa Sudut } \\
\text { (detik) }\end{array}$ & $\begin{array}{c}\text { Dengan Sudut } \\
\text { (detik) }\end{array}$ & $\begin{array}{c}\text { Tanpa Sudut } \\
(\%)\end{array}$ & $\begin{array}{c}\text { Dengan Sudut } \\
(\%)\end{array}$ \\
\hline \multirow{3}{*}{ User 1 } & Ruangan 1 & 6,85 & 7,15 & 90 & 90 \\
\cline { 2 - 6 } & Ruangan 2 & 5,8 & 6,75 & 85 & 95 \\
\cline { 2 - 6 } & Ruangan 3 & 6,55 & 7,2 & 90 & 95 \\
\hline \multirow{3}{*}{ User 2 } & Ruangan 1 & 6,85 & 7,3 & 90 & 90 \\
\cline { 2 - 6 } & Ruangan 2 & 6,45 & 6,85 & 90 & 95 \\
\cline { 2 - 6 } & Ruangan 3 & 7 & 7,25 & 95 & 95 \\
\hline
\end{tabular}

Pengukuran untuk output sistem dengan sumber api sejauh $30 \mathrm{~cm}$ dari receiver sensor tidak terjadi pengiriman notifikasi dikarenakan threshold teganganyang sudah ditentukan pada syntax yang dimasukkan pada command untuk Arduino UNO. Tabel 7 menunjukkan persentase keberhasilan penerimaan notifikasi oleh user lebih dari 80 persen, dan waktu penerimaan notifikasi baik itu tanpa sudut maupun dengan sudut berada dibawah 10 detik. Waktu penerimaan notifikasi ini merupakan delay yang terjadi pada saat mulai terdeteksi sumber gejala dini kebakaran, pemrosesan sistem, pengiriman notifikasi, sampai notifikasi diterima oleh user untuk menyatakan bahwa terdeteksi kebakaran dan juga posisi awal terjadinya kebakaran.

Adapun lama delay yang berbeda pada masing-masing ruangan dan user dikarenakan dalam penerimaan notifikasi terdapat sistem antrian pada trafik jaringan telekomunikasi seluler GSM (Global System for Mobile Communication). Antrian trafik ini berada pada BTS (Base Transceiver Station), BSC (Base Station Controller), MSC (Mobile Station Center) dan SMSC (Short Message Service Center). Antrian trafik ini juga dikarenakan provider yang menyediakan jaringan lebih memprioritaskan panggilan telepon dibandingkan text message. Kegagalan dalam pengiriman SMS dan penerimaan SMS yang dikarenakan text message bukan merupakan prioritas utama dibandingkan panggilan suara pada provider jaringan. Kegagalan penerimaan SMS juga disebabkan SMSC menerima pemberitahuan yang dikirimkan oleh HLR (Home Locator Register) bahwa nomor yang dituju sedang tidak aktif atau diluar jaringan komunikasi seluler.

Waktu rata-rata yang berada dibawah 10 detik dan keberhasilan penerimaan notifikasi lebih dari 80 persen dari sistem ini, mampu mempercepat respon user (khususnya pemadam kebakaran) dalam menanggapi notifikasi dibandingkan menunggu panggilan dari seseorang yang harus menyaksikan terjadinya kebakaran kemudian melakukan panggilan melalui telepon. 


\section{KESIMPULAN}

Dari penelitian ini dapat disimpulkan bahwa sistem ini :

1. Keluaran sensor api berupa sinyal DC (Direct Current).

2. Sensor api mampu mendeteksi api dengan jarak sejauh $30 \mathrm{~cm}$ dan dengan sudut pendeteksian 30 derajat.

3. Sumber api yang semakin jauh dari sensor api membuat tegangan yang terukur semakin membesar, sebanding dengan menurunnya intensitas cahaya api.

4. Sensor asap mampu mendeteksi asap dikarenakan rata-rata tegangan yang terukur saat mendeteksi asap sebesar 4,48 volt sedangkan saat tidak mendeteksi asap sebesar 0,72 volt.

5. Sistem memiliki keberhasilan dalam penerimaan notifikasi pada user lebih dari 80 persen dengan waktu penerimaan dibawah 10 detik.

\section{DAFTAR PUSTAKA}

[1] Agung K., A. dkk. 20. Perancangan Dan Implementasi Sistem Peringatan Bencana Kebakaran Menggunakan Teknologi Wireless Sensor Network (WSN) Berbasis ZIGBEE (IEEE 802.15.4). Bandung : Institut Teknologi Telkom Bandung.

[2] Arkan, F. 2014. Sistem Detektor Kebakaran untuk Rumah Susun dengan Sistem Wireless Sensor Network. Bangka Belitung : Universitas Bangka Belitung.

[3] Babu, Prof K. Ashok. 2012. Forest Fire Prevention Using Wireless Sensor Networks. Sheriguda : Sri Indu College of Engg and Tech.

[4] Hariyawan, M. Yanuar. dkk. 2013. Sistem Pendeteksi Dini Kebakaran Hutan Berbasis Wireless Sensor Network. Riau : Politeknik Caltex Riau.

[5] Jusak. 2013. Implementasi ZIGBEE IEEE 802.15.4 Untuk Pemantauan Suhu dan Kelembapan Udara. Surabaya : STMIK STIKOM Surabaya.

[6] Lewis, F.L. 2004. Wireless Sensor Networks. Arlington : The University of Texas.

[7] Netalia, E. WSN (Wireless Sensor Network). Bandung : Politeknik Telkom Bandung.

[8] Sha, Kewei. dkk. Using Wireless Sensor Networks for Fire Rescue Application : Requirements and Challenges. Detroit : Wayne State University.

[9] Sumadi. dkk. 2013. Analisis dan Implementasi Sistem Pemantauan Kebakaran Menggunakan Jaringan Sensor Nirkabel IEEE 802.15.4. Bandung : Telkom University Bandung.

[10] Yongsheng, Liu, dkk. 2011. A Novel Accurate Forest Fire Detection System Using Wireless Sensor Networks. China : Fuzhou University.

[11] http://www.arduino.cc/ [diakses pada 11 Mei 2015].

[12] http://www.ni.com/wsn/whatis/ [diakses pada 11 Mei 2015]. 